\title{
Genetic Engineering of the
} Biosynthesis of Glycine Betaine Modulates Phosphate Homeostasis by Regulating Phosphate Acquisition in Tomato

\author{
Daxing Li ${ }^{1}$, Tianpeng Zhang ${ }^{1}$, Mengwei Wang ${ }^{1}$, Yang Liu' ${ }^{1}$, Marian Brestic ${ }^{2}$, \\ Tony H. H. Chen ${ }^{3}$ and Xinghong Yang ${ }^{1 *}$
}

${ }^{1}$ College of Life Science, State Key Laboratory of Crop Biology, Shandong Key Laboratory of Crop Biology, Shandong Agricultural University, Tai'an, China, ${ }^{2}$ Department of Plant Physiology, Slovak University of Agriculture, Nitra, Slovakia, ${ }^{3}$ Department of Horticulture, Oregon State University, Corvallis, OR, United States

OPEN ACCESS

Edited by:

Mukesh Jain,

Jawaharlal Nehru University, India

Reviewed by:

Jitender Giri,

National Institute of Plant Genome Research (NIPGR), India

Ananda Mustafiz,

South Asian University, India

*Correspondence:

Xinghong Yang

xhyang@sdau.edu.cn

Specialty section: This article was submitted to

Plant Abiotic Stress,

a section of the journal

Frontiers in Plant Science

Received: 11 June 2018 Accepted: 21 December 2018

Published: 10 January 2019

Citation:

Li D, Zhang T, Wang M, Liu Y, Brestic M, Chen THH and Yang $X$ (2019) Genetic Engineering of the

Biosynthesis of Glycine Betaine Modulates Phosphate Homeostasis by Regulating Phosphate Acquisition in Tomato. Front. Plant Sci. 9:1995.

doi: 10.3389/fp/s.2018.01995
Glycine betaine (GB), as a putative compatible substance, protects plants against the damaging effects of abiotic stresses. Phosphorus deficiency is one type of abiotic stress that is detrimental to plant growth. Maintenance of phosphate (Pi) homeostasis is crucial. This study demonstrates GB-regulated phosphate homeostasis in the tomato (Solanum lycopersicum cv. 'Moneymaker') transformed with the choline oxidase gene codA from Arthrobacter globiformis. The codA-transgenic lines displayed more resistance to low-phosphate stress. The data revealed that the wild-type plants were stunted and consistently retained less Pi than transgenic lines, especially when grown under low-phosphate conditions. This difference in Pi retention was attributable to the enhanced $\mathrm{Pi}$ uptake ability in the transgenic lines. The transgenic plants translocated more $\mathrm{Pi}$ into the plant cell due to the enhanced enzymatic activity of plasma membrane $\mathrm{H}^{+}$-ATPase and increased $\mathrm{Pi} / \mathrm{H}^{+}$co-transport, which improved $\mathrm{Pi}$ uptake. The differential expression of 'PHO regulon' genes further maintained intracellular $\mathrm{Pi}$ homeostasis. Furthermore, GB maintained a higher photosynthesis rate, thus increasing the production and translocation of sucrose via phloem loading to enhance plant response to low-phosphate stress. We conclude that GB mediates Pi uptake and translocation by regulating physiological and biochemical processes that promote adaptation to environmental changes in $\mathrm{Pi}$ availability. These processes eventually lead to better growth and development of the codA-transgenic lines. This finding will help to further elucidate the signaling mechanism of how GB perceives and transmits low-phosphate signals to alleviate Pi nutritional stress.

Keywords: glycinebetaine, codA gene, low phosphate stress, phosphate homeostasis, phosphate acquisition, tomato

\section{INTRODUCTION}

As an essential macronutrient, phosphorus is required for plant growth, development, and metabolism (Raghothama, 1999; Vance et al., 2003; Pandey et al., 2017). Phosphorus not only serves as the backbone for the biosynthesis of nucleic acids, membranes, phospholipids and ATP but also participates in many important biochemical pathways, including signal transduction, regulation of 
enzymatic activities, photosynthesis, and oxidative phosphorylation (Hamburger et al., 2002; Shin et al., 2004; Ai et al., 2009; Shen et al., 2011; Song et al., 2016). While the phosphorus content of the soil may be high, phosphorus deficiency can still arise due to precipitation and mineralization processes (Richardson, 1994; Yuan et al., 2017). Approximately $70 \%$ of global cultivated land is subjected to Pi deficiency (LópezArredondo et al., 2014). Thus, low phosphorus availability is a major constraint for plant growth and productivity (Mehra et al., 2016; Pandey et al., 2017). Inorganic phosphate is the only form of phosphorus that can be assimilated by plants (Chiou and Lin, 2011; Nussaume et al., 2011; LópezArredondo et al., 2014). Although Pi may fluctuate widely in soils, intracellular concentrations of $\mathrm{Pi}$ are strictly regulated to maintain homeostasis in plants (Chiou and Lin, 2011). To cope with phosphorus deficiency, plants have evolved a series of sophisticated strategies to maintain stable cellular $\mathrm{Pi}$ concentrations (Lin et al., 2009). These strategies involve physiological, biochemical and molecular responses, including the modification of root system architecture (i.e., reduction of primary root growth and the formation of more lateral roots and root hairs) (Watanabe et al., 2006; Lin et al., 2009; Lei et al., 2011; Mehra et al., 2016); the induction and secretion of acid phosphatases (APases) (Tian et al., 2003; Xiao et al., 2006; Wang X. et al., 2009; Mehra et al., 2017; Pandey et al., 2017), RNase (Löffler et al., 1992, 1993; Lin et al., 2009; Plaxton and Tran, 2011; López-Arredondo et al., 2014; Yuan et al., 2017), organic acid or protons $\left(\mathrm{H}^{+}\right)$(Otani et al., 1996; Yun and Kaeppler, 2001; López-Arredondo et al., 2014) into the rhizosphere contribute to the release of Pi from some organic sources; enhanced expression of high-affinity $\mathrm{Pi}$ transporter genes (Liu et al., 1998; Pandey et al., 2017) and establishment of differential photosynthate distribution between shoots and roots, resulting in increased root growth (Yun and Kaeppler, 2001; Gong et al., 2011; Yuan et al., 2017). In addition, Mehra et al. (2016) proposed that plant release $\mathrm{Pi}$ from membrane phospholipids through global membrane lipid remodeling under Pi deficiency. Mehra et al. (2017) also revealed the role of a novel rice purple acid phosphatases in improving plant utilization of organic-phosphorus. Recently, more adaptive strategies have been proved.

As is well-known, glycine betaine (GB) is one of the best-studied compatible solutes that enables plants to tolerate abiotic stress (Chen and Murata, 2002, 2008, 2011; Giri, 2011). Some studies have confirmed that GB has multiple functions in plant survival and growth, under both stressful and normal conditions (Yang et al., 2005, 2008; Park et al., 2007; Giri, 2011; Li et al., 2011; Masood et al., 2016; Kumar et al., 2017). However, few studies suggested that GB also interacts with mineral nutrition. Li et al. (2014) presented a new mechanism by which GB participates in salt stress tolerance. They indicated that GB acted as a cofactor of the $\mathrm{Ca}^{2+}$-CaM signal transduction pathway under salt stress. Wei et al. (2017) demonstrated that GB might regulate ion channel and transporters, resulting in high potassium and low sodium levels to enhance salt tolerance in transgenic plants under salt stress conditions. Nevertheless, the interaction between GB and phosphorus nutrition is still largely unknown. Several studies suggest that GB protects photosynthetic processes in stressful environments (Yang et al., 2007; Khan et al., 2009; Masood et al., 2016). In addition, phosphorus deficiency has immediate and direct consequences for photosynthesis (Plaxton and Carswell, 1999; Hammond and White, 2008). Therefore, we hypothesized that there may be a relationship between GB and phosphorus, and GB may play an important role in phosphate homeostasis.

In this study, we used $\operatorname{cod} A$-transgenic tomato plants, which were transformed with the choline oxidase gene $\operatorname{cod} A$ from Arthrobacter globiformis. GB was accumulated in vivo as material to explore the mechanism used to enhance plant tolerance to phosphorus deficiency. Our results suggested that GB accumulation in vivo modulates phosphate homeostasis by regulating phosphate translocation and acquisition in tomato plants. Our findings shed light on the important role of GB in plant adaptation to low phosphate conditions and provide a new direction to explore the mechanisms by which GB modulates mineral nutrition.

\section{MATERIALS AND METHODS}

\section{Plants Materials, Growth Conditions, and Stress Treatment}

The $\operatorname{codA}$-transgenic tomato plants (L2, L3, and L4) and wild-type (WT) tomato plants (Solanum lycopersicum cv. 'Moneymaker') were used in this study. Our and others previous studies indicated the wide-type tomato plants are considered non-accumulators of GB (Park et al., 2004; Li et al., 2011; Kurepin et al., 2015; Kumar et al., 2017). The L2, L3, and L4 transgenic tomato plants were transformed with a gene $(\operatorname{cod} A)$ for choline oxidase (Park et al., 2007). The seedlings (after germination) were grown in pots with sand containing the modified Hoagland's solution. The seedlings were treated with $1.0 \mathrm{mM}$ phosphorus (CK), $0.2 \mathrm{mM}$ phosphorus, and $0.02 \mathrm{mM}$ phosphorus (LP) for 15 days under sand-culture system. The nutrient solution was renewed every 3 days. The plants were grown in greenhouse at $25 / 20^{\circ} \mathrm{C}$ (day/night) with a photosynthetic photon flux density of $500 \mu \mathrm{mol} \mathrm{m} \mathrm{m}^{-2} \mathrm{~s}^{-1}$, a relative humidity of $65-70 \%$ and a photoperiod of $16 / 8 \mathrm{~h}$ light/dark.

\section{Extraction and Quantification of GB}

The seedlings treated under normal or low-phosphate stress conditions for 15 days were used in this experiment. The GB content was measured following Rhodes et al. (1989) with some modifications. Leaf samples (four biological replicates were used in each genotype) were ground in methanol:chloroform:water $(12: 5: 1)$ at $60^{\circ} \mathrm{C}$ for $30 \mathrm{~min}$. The aqueous phase was fractionated by ion-exchange chromatography. After that, the GB fraction was eluted with $4 \mathrm{M} \mathrm{NH} \mathrm{NH}_{4} \mathrm{OH}$ and dried on a rotary evaporator. Then, the preliminarily purified extract of betaine was analyzed by high-performance liquid chromatography (HPLC) and Millennium Chromatography Manager System Control software 
on a liquid chromatograph (SCL-10AVP; Japan) equipped with a Hypersil 10 SCX column.

\section{Determination of the Net Photosynthetic Rate (Pn)}

Measurements of the Pn were performed at the same leaf position of the tomato plants in the morning between 9:00 and 11:00 at the seedling stage for different Pi concentrations. For each combination of genotype and $\mathrm{Pi}$ treatment, six biological repeats were performed. We used a portable photosynthetic system (CIRAS-3, PP Systems, Hitchin, United Kingdom) under the following conditions: $380 \mu \mathrm{l} \mathrm{L}-1$ $\mathrm{CO}_{2}, 800 \mu \mathrm{mol} \mathrm{m} \mathrm{m}^{-2} \mathrm{~s}^{-1}$ photosynthetic photon flux density, a leaf temperature of $25 \pm 1^{\circ} \mathrm{C}$ and a relative air humidity of 60-70\%.

\section{Determination of the Sucrose and Starch Content}

The leaf content of sucrose and starch was determined using a kit from Nanjing Jiancheng Bioengineering Institute. For sucrose analysis, tomato plant samples (leaves) were extracted in $1 \mathrm{~mL}$ of $80 \%$ ethanol $(\mathrm{v} / \mathrm{v})$ for $10 \mathrm{~min}$ at $80^{\circ} \mathrm{C}$ in a water bath, and the samples were centrifuged at $4000 \mathrm{~g}$ for $10 \mathrm{~min}$ at $25^{\circ} \mathrm{C}$. For destaining, $2 \mathrm{mg}$ active carbon was added to the supernatant at $80^{\circ} \mathrm{C}$ for $30 \mathrm{~min}$. Then, $1 \mathrm{~mL} 80 \%$ ethanol ( $\mathrm{v} / \mathrm{v})$ was added and the samples were centrifuged at $4000 \mathrm{~g}$ for $10 \mathrm{~min}$ at $25^{\circ} \mathrm{C}$ and the supernatant was analyzed.

For starch analysis, tomato plant samples (leaves) were thoroughly ground in $1 \mathrm{~mL} 80 \%$ ethanol $(\mathrm{v} / \mathrm{v})$ and then treated for $30 \mathrm{~min}$ at $80^{\circ} \mathrm{C}$ in a water bath. Samples were centrifuged at $3000 \mathrm{~g}$ for $5 \mathrm{~min}$ at $25^{\circ} \mathrm{C}$, and the residue was retained (the supernatant was discarded). Next, $0.5 \mathrm{~mL}$ of water was added, and the samples were incubated in a water bath for $15 \mathrm{~min}$ at $95^{\circ} \mathrm{C}$. After cooling, the tissue residue was digested with $0.35 \mathrm{~mL}$ perchloric acid at $25^{\circ} \mathrm{C}$ for $30 \mathrm{~min}$ and oscillated 3-5 times. After that, $0.5 \mathrm{~mL}$ water was added, the samples were centrifuged at $3000 \mathrm{~g}$ for $10 \mathrm{~min}$ at $25^{\circ} \mathrm{C}$, and the supernatant was analyzed.

The content of sucrose and starch were measured in three independent samples for each line. Statistical analysis was performed using Student's $t$-test.

\section{Quantitative Measurements of Anthocyanin}

The anthocyanin was extracted using a methanol-HCl method according to Rabino and Mancinelli (1986) with slight modifications. Tomato plant samples $(0.2 \mathrm{~g}$, three biological replicates for each condition) were incubated in $1 \mathrm{~mL}$ of acidic methanol (MeOH, HPLC quality) solution, consisting of $80 \%$ $(\mathrm{v} / \mathrm{v}) \mathrm{MeOH}, 0.16 \%(\mathrm{~m} / \mathrm{v})$ ascorbic acid, $0.16 \%(\mathrm{~m} / \mathrm{v})$ t-butyl hydroquinone, and $0.1 \%(\mathrm{~m} / \mathrm{m}) \mathrm{HCl}$, with gentle shaking for $18 \mathrm{~h}$ at room temperature. After centrifugation at $12000 \mathrm{~g}$ for $2 \mathrm{~min}, 0.4 \mathrm{~mL}$ of supernatant was added to $0.6 \mathrm{~mL}$ acidic methanol and then the sample was filtered through a $0.22 \mu \mathrm{m}$ filter before analysis. Extract absorbance was measured at 530 and $657 \mathrm{~nm}$.

\section{Determination of the Activity of Sucrose Phosphate Synthase (SPS) and Sucrose Synthase (SS)}

The enzymatic activities of SPS and SS for leaves were determined using a kit from Nanjing Jiancheng Bioengineering Institute. Three independent experiments were carried out per condition.

\section{Measurement of Fresh Weight, Total Phosphorus Content, and $\mathrm{Pi}$ Content}

The tomato plants were treated under different Pi conditions for 15 days. After that plants were collected and then weighed.

The phosphorus concentrations of whole plants and the $\mathrm{Pi}$ content in the leaf, stem and root samples were determined colorimetrically by the molybdenum blue method, but the phosphorus concentration was measured after digestion in a mixture of $\mathrm{H}_{2} \mathrm{SO}_{4}-\mathrm{H}_{2} \mathrm{O}_{2}$ (Ames, 1966; Lei et al., 2011). For each combination of genotype and Pi treatment, three biological replicates were used.

\section{Plasma Membrane $\mathrm{H}^{+}$-ATPase Activity and $\mathrm{Net}^{+} \mathrm{H}^{+}$Flux in the Root Tip of Tomato Plants}

The root plasma membrane isolation was performed following Yan et al. (2002) with some modifications. The root plasma membrane was stored at $-80^{\circ} \mathrm{C}$ until analysis. The membrane protein concentration was quantified using the method Bradford (1976). Root plasma membrane $\mathrm{H}^{+}$-ATPase activity was measured according to the method of Yan et al. (2002). To assess the purification of $\mathrm{H}^{+}$-ATPase activity, $\mathrm{H}^{+}$-ATPase activity was expressed as the difference in activity between the presence and absence of $0.1 \mathrm{~mm}$ vanadate. A number of roots were collected for the extraction of plasma membrane, the total extractions were divided into three parts, and three replicates of total extracted plasma membranes of each treated plants of WT and transgenic plants were used for further determination of $\mathrm{H}^{+}$-ATPase activity. Finally, the plasma membrane extraction and the $\mathrm{H}^{+}$-ATPase activity determination experiments were repeated for three times.

The net fluxes of $\mathrm{H}^{+}$were measured by Non-invasive Micro-test Technology (NMT) (NMT100 Series, Younger USA LLC, Amherst, MA, United States). For each line, six independent samples were measured. $\mathrm{H}^{+}$flux measurements were recorded for 10 min, and $\mathrm{H}^{+}$flux data were calculated with Mage Flux ${ }^{1}$.

\section{Quantitative Real-Time PCR Analysis}

Total RNA was extracted from $100 \mathrm{mg}$ of leaves and roots from WT and $\operatorname{codA}$-transgenic tomato plants (L2, L3, and L4) using TRIzol reagent (TransGen Biotech; China). First-strand cDNA was synthesized from $1 \mu \mathrm{g}$ of total RNAs using a reverse transcription system from TaKaRa. Q-PCR was performed

\footnotetext{
${ }^{1}$ http://xuyue.net/mageflux
} 
using a SYBR ${ }^{\circledR}$ PrimeScript $^{\mathrm{TM}}$ RT-PCR Kit (TaKaRa; China) in a $20 \mu \mathrm{L}$ volume on the Bio-Rad CFX96 real-time PCR detection system. The quantitative real-time PCR experiment was repeated at least three times under identical conditions, using the housekeeping gene (actin) as an internal control. Primers used in the experiment are listed in Supplementary Table S1.

\section{RESULTS}

\section{GB Enhances Tolerance to Low-Phosphate in Transgenic Plants}

Previous results showed that GB improved plant performance against environmental stresses (Ahmad et al., 2013). We wondered whether GB plays a role in tomato plants responses to low-phosphate stress. First, we measured the accumulation of GB in transgenic and WT tomato plants. Quantitative HPLC analysis demonstrated that the contents of GB in three independent transgenic lines ranged from 1.5 to $2.5 \mu \mathrm{mol} \mathrm{g}^{-1}$ FW, while GB was undetectable in WT plants (Figure 1). According to the result of Figures 2A-C, no significant differences in the phenotype or biomass were observed between the $\operatorname{cod} A$-transgenic tomato plants (L2, L3, and L4) and WT plants under normal conditions $(1.0 \mathrm{mM})$. Under low-phosphate conditions $(0.2$ and $0.02 \mathrm{mM})$, the growth of transgenic plants and WT plants was inhibited (Figures 2A,B), but transgenic plants were significantly less affected than WT plants and showed the higher biomass of tomato plants (Figure 2C). These results indicate that the $\operatorname{cod} A$-transgenic tomato plants were more tolerant to low-phosphate stress than WT plants. To respond to low-phosphate stress, plants also induce anthocyanin and starch accumulation. Quantitative analysis showed that, under low-phosphate conditions, anthocyanin and starch content in transgenic tomato plants were less than in WT plants (Figures 2D,E). All the above indicate that GB

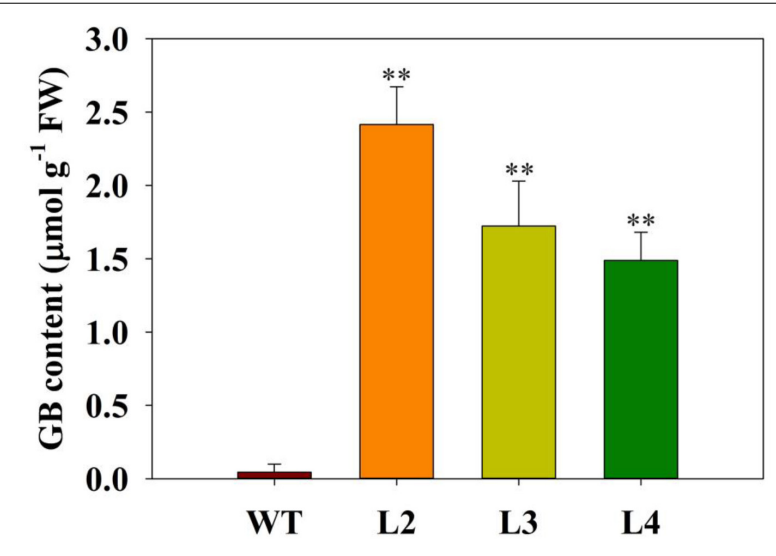

FIGURE 1 | Levels of glycine betaine (GB) in the leaves of wild-type (WT) plants and three codA-transformed tomato lines ( $L 2$, L3, and L4). Plants were treated under normal or low-phosphate stress conditions for 15 days. Values represent the means $\pm S D$ of four replicates. Asterisks indicate significant differences compared with WT plants (Student's t-test). FW, fresh weight; ${ }^{*} P<0.05 ;{ }^{* *} P<0.01$. affects multiple aspects of plant response to low-phosphate conditions.

\section{GB Participates in the Metabolism of Sucrose in Transgenic Plants}

Some studies have shown that sucrose may play an important role in the modulation of phosphorus metabolism under low phosphorus stress (Hammond and White, 2008; Lei et al., 2011). Therefore, we measured some physiological indexes of sucrose metabolism in WT and transgenic tomato plants to examine the role of GB in the adaptation response to low phosphate. The sucrose content in the leaves of $\operatorname{codA}$-transgenic tomato plants was significantly higher than that of WT plants (Figure 3A). To further confirm whether the difference in sucrose content is caused by synthesis and/or transport, and the activity of sucrose synthase (SS) and sucrose phosphate synthase (SPS), which are enzymes that participate in synthesizing sucrose for sucrose loading into phloem, was determined in leaves of WT and $\operatorname{codA-}$ transgenic tomato plants (Figures 3B,C). Under Pi-deficient conditions, the activities of SS and SPS were significantly higher in $\operatorname{cod} A$-transgenic plants than in WT plants (Figures $3 \mathrm{~B}, \mathrm{C}$ ). In addition, we also tested the expression of SUC2, which encodes a sucrose-proton symporter that is capable of transporting sucrose (Lloyd and Zakhleniuk, 2004), and the results indicated that SUC2 was induced under low-phosphate conditions and that its expression in transgenic plants was far greater than that of WT plants (Figure 3D). These results suggested that GB may affect sucrose metabolism as a response to low-phosphate conditions.

\section{GB Maintains Higher Photosynthesis in Transgenic Plants}

To verify the elevated levels of sucrose in transgenic plants, we further analyzed photosynthesis under different $\mathrm{Pi}$ concentrations. Only under normal Pi levels (1.0 mM; Figure 4) did the transgenic plants appear similar to the WT plants. As the Pi concentration decreased, photosynthesis in the WT plants was severely inhibited. In contrast, photosynthesis has been maintained at an elevated level in the $\operatorname{cod} A$-transgenic plants even when they were grown under a very low Pi level $(0.02 \mathrm{mM}$; Figure 4), indicating that GB may be involved in low-phosphate response, thus influencing photosynthesis.

\section{GB Affects Phosphorus Accumulation in Transgenic Plants}

To sustain normal growth and development, it is important for plants to have enough phosphorus. We noted above that the transgenic plants adapted well to the low-phosphate condition. With the decreased $\mathrm{Pi}$ concentrations during growth, the total phosphorus in WT plants dramatically decreased, but the total phosphorus content in transgenic plants remained high (Figure 5A). To test whether the transgenic plants are better at absorbing and utilizing $\mathrm{Pi}$, we measured the $\mathrm{Pi}$ content of various parts in both WT and transgenic plants. In all cases, the transgenic plants consistently retained more Pi compared with the WT plants (Figures 5B-D). These results suggest that 
A
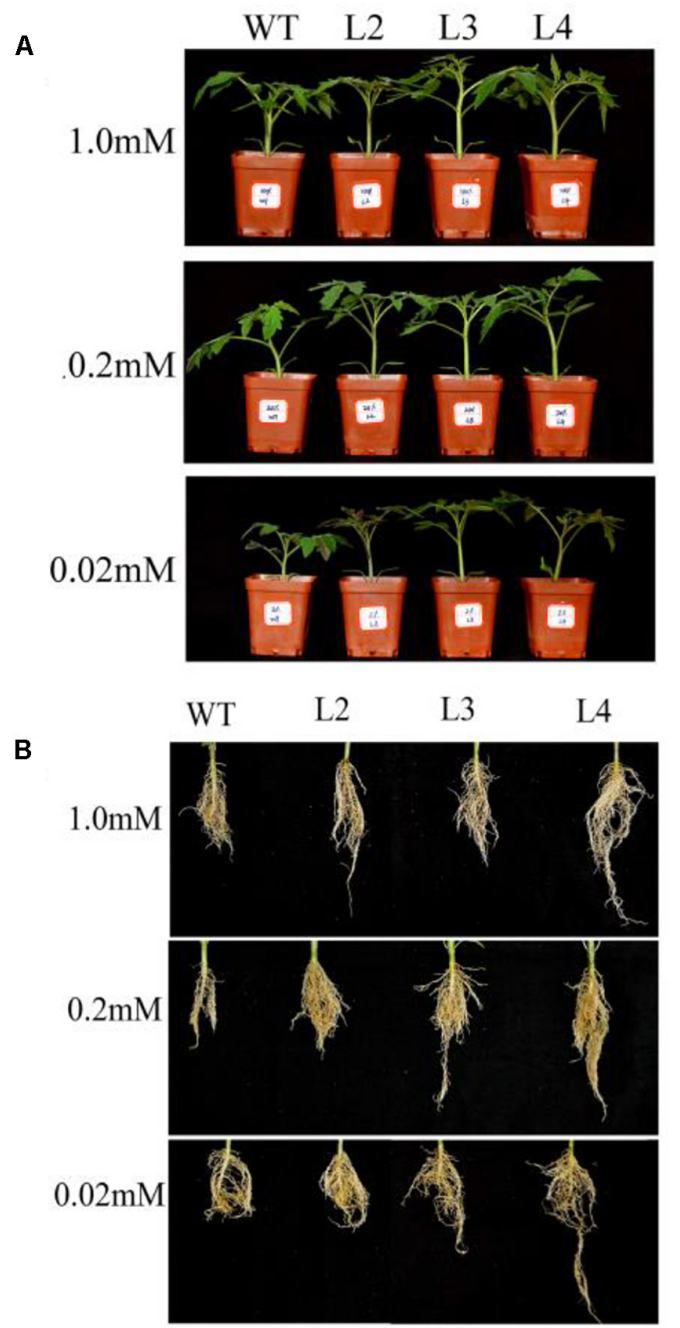

C
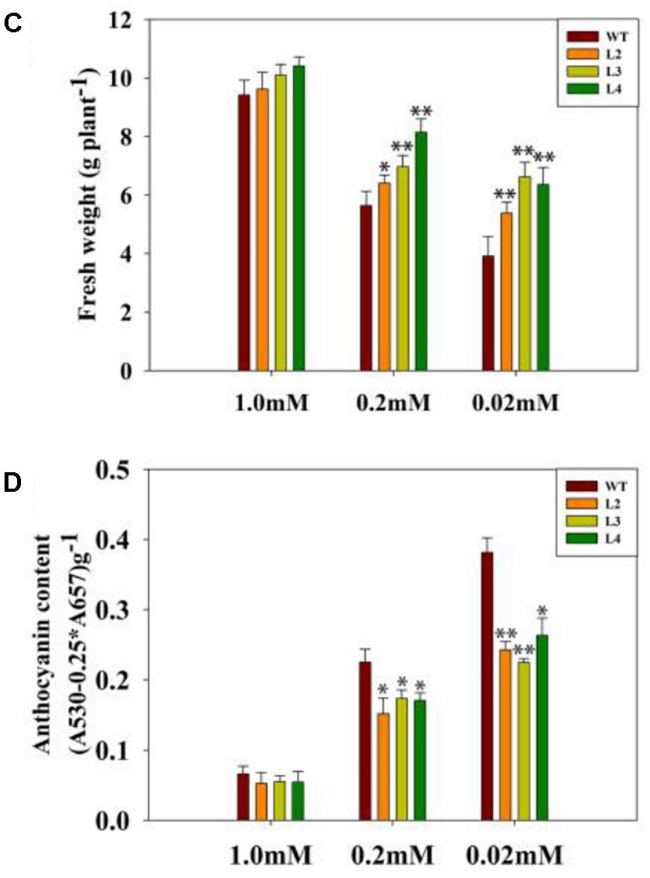

E

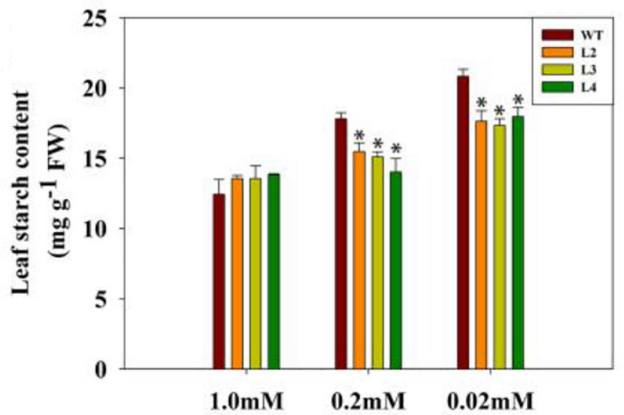

FIGURE 2 | Growth phenotype of WT and transgenic lines under variable Pi conditions. (A,B) The shoot and root phenotypes of 15-day-old WT tomato plant and three codA-transgenic tomato lines under variable Pi conditions. Seedlings (after germination) were treated with $1.0 \mathrm{mM}$ phosphorus (CK), $0.2 \mathrm{mM}$ phosphorus and $0.02 \mathrm{mM}$ phosphorus (LP) for 15 days under sand-culture system. Then, photos were taken. (C) The whole-plant biomass of WT and transgenic lines under the various Pi concentrations as described in (A,B). 15-day-old tomato seedlings were collected for biomass analysis. Values are means \pm SD. $n=12$ for each genotype. (D) Anthocyanin content in the leaves of plants treated with 1.0, 0.2, $0.02 \mathrm{mM}$ phosphorus for 15 days; seedlings were subsequently harvested for measuring anthocyanin content. (E) Starch accumulation of the 15-day-old WT and transgenic lines described in (D). Values represent means \pm SD of three replicates. Asterisks indicate significant differences compared with WT plants (Student's $t$-test). FW, fresh weight; ${ }^{*} P<0.05 ;{ }^{* *} P<0.01$.

GB may enhance the absorption of elemental phosphorus in transgenic plants under low-phosphate conditions.

\section{GB Activates Plasma Membrane $\mathrm{H}^{+}$-ATPase in Transgenic Plants}

Transport of $\mathrm{Pi}$ across the plasma membrane is regulated by $\mathrm{Pi} / \mathrm{H}^{+}$co-transport stimulated by $\mathrm{H}^{+}$-ATPase activity (Raghothama, 2000). Phosphorus elemental analysis of tomato plants suggested that GB potentially functions in Pi absorption and utilization. To further support this hypothesis, we measured the activity of $\mathrm{H}^{+}$-ATPase in WT plants and transgenic plants. To evaluate the purity of root plasma membrane in tomato plants, the activity of various inhibitor-sensitive ATPases in the membrane fraction was analyzed (Table 1). As described in previous studies (Yan et al., 2002; Xu et al., 2012), our results showed that vanadate-sensitive ATPase occupied approximately $90 \%$ of the total activity in the plasma membrane, which indicated a highly purified plasma membrane. Afterward, plasma membrane $\mathrm{H}^{+}$-ATPase activity was analyzed in the whole root of WT plants and transgenic lines (Figure 6). Under normal conditions, no significant difference in $\mathrm{H}^{+}$-ATPase activity in the root plasma membrane was observed between the codA-transgenic plants and WT plants. However, the activity of root plasma membrane $\mathrm{H}^{+}$-ATPase in transgenic plants was clearly higher than that in WT plants under low-phosphate stress (Figure 6). Generally, protons $\left(\mathrm{H}^{+}\right)$in the plant cells are pumped out by the plasma membrane $\mathrm{H}^{+}$-ATPase (Zhang et al., 2011). 
A

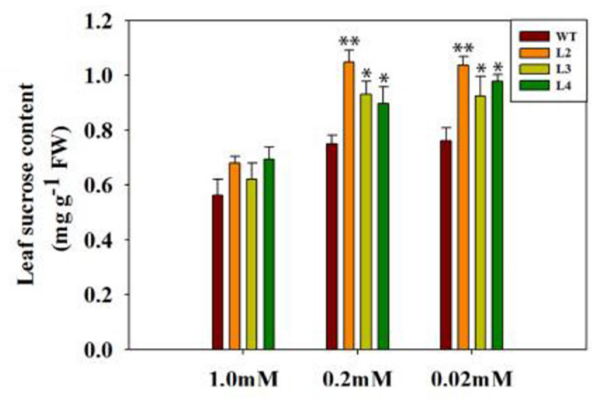

C

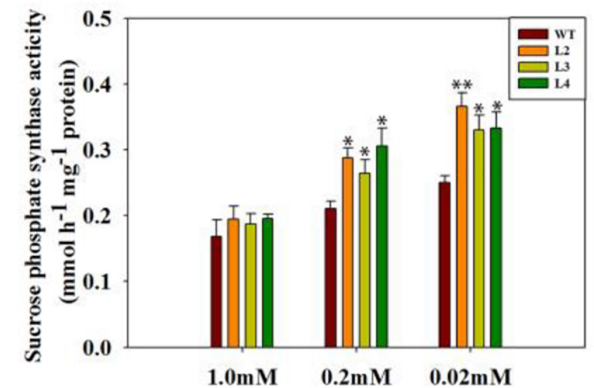

B

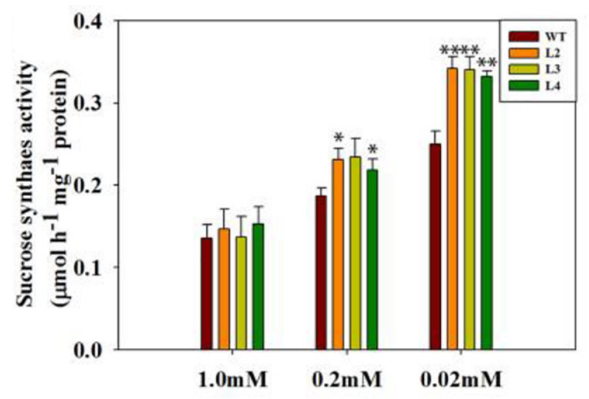

D

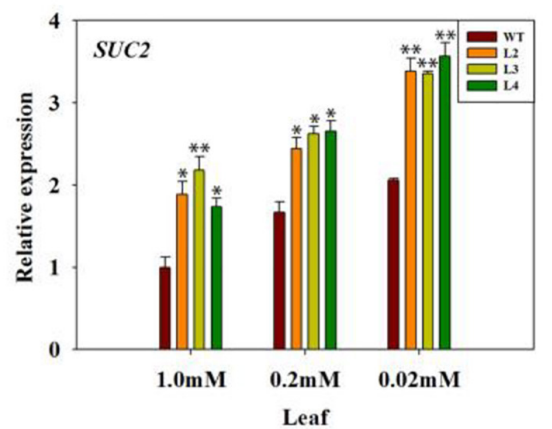

FIGURE 3 | Sucrose concentration (A), SS and SPS activity (B,C) and leaf SUC2 gene expression (D) in WT tomato plants and three codA-transgenic tomato lines under variable Pi conditions. Seedlings (after germination) were treated with $1.0 \mathrm{mM}$ phosphorus (CK), $0.2 \mathrm{mM}$ phosphorus and $0.02 \mathrm{mM}$ phosphorus (LP) for 15 days under sand-culture system. The seedlings were subsequently used for experimental analysis. Values represent means $\pm S D$ of three replicates. Asterisks indicate significant differences compared with WT plants (Student's $t$-test). SS, sucrose synthesis; SPS, sucrose phosphate synthesis; FW, fresh weight; ${ }^{*} P<0.05$; ${ }^{* *} P<0.01$

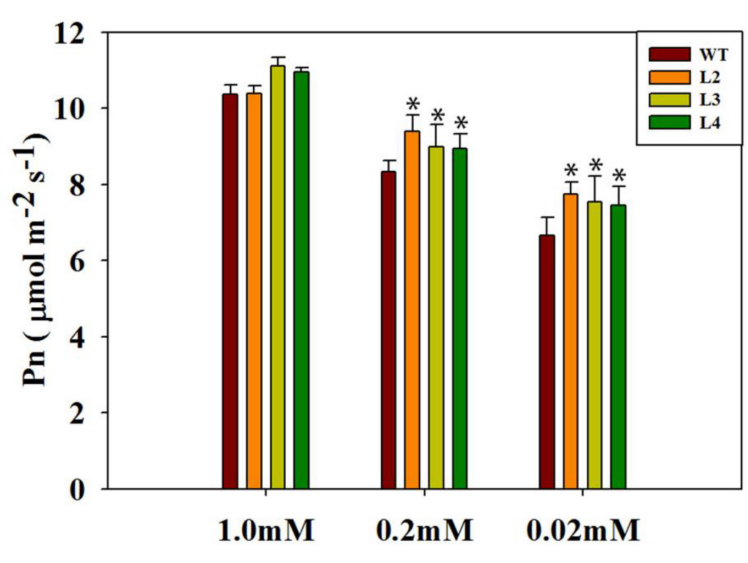

FIGURE 4 | Photosynthetic rate (Pn) of leaves of plants grown with normal or low phosphorus. Seedlings (after germination) were treated with $1.0 \mathrm{mM}$ phosphorus (CK), $0.2 \mathrm{mM}$ phosphorus and $0.02 \mathrm{mM}$ phosphorus (LP) for 15 days under sand-culture system. The photosynthetic rate was measured by the CIRAS-3. Values are means \pm SD. $n=6$ for each genotype. Asterisks indicate significant differences compared with WT plants (Student's $t$-test). ${ }^{*} P<0.05 ;{ }^{* *} P<0.01$.

These results partially suggested that the transgenic plants with enhanced $\mathrm{H}^{+}$-ATPase activity may have a stronger ability to secrete more $\mathrm{H}^{+}$to regulate $\mathrm{Pi}$ absorption.

The proton $\left(\mathrm{H}^{+}\right)$could couple with Pi to carry out Pi transport (Zhang et al., 2011). The relationship between Pi uptake and plasma membrane $\mathrm{H}^{+}$-ATPase activity was examined further by analyzing proton flux along the root tip of WT plants and $\operatorname{cod} A$-transgenic plants (Figure 7). We found that no significant difference in $\mathrm{H}^{+}$influx was observed between transgenic plants and WT plants under normal conditions. Nevertheless, the $\mathrm{H}^{+}$ influx in $\operatorname{cod} A$-transgenic plants was significantly higher than WT plants at the root tip under low-phosphate stress (Figures 7C-F). These results indicate that GB accumulation in vivo increases the $\mathrm{H}^{+}$influx, to promote Pi absorption in the root.

\section{GB Mediates the Expression of Pi Uptake and Translocation Related Genes in Transgenic Plants}

In addition, PHT1 transporters are responsible for Pi uptake from the soil (Hammond and White, 2008; Bucher and Fabiańska, 2016). SlPT1 and SlPT2, members of the PHT1 family, are major high affinity $\mathrm{Pi} / \mathrm{H}^{+}$symporters in tomato whose expression is also highly induced by Pi starvation (Liu et al., 1998; Chen et al., 2014). Consistent with this observation, transcription of SIPT1 and SIPT2 was clearly induced in the $\operatorname{cod} A$-transgenic lines (Figures 8A,B), especially in the $0.02 \mathrm{mM}$ treatment. In contrast, the same genes were expressed at a lower level in the WT plants. This result indicates that the induction of SIPT1 and SIPT2 in $\operatorname{codA}$-transgenic lines was partially caused by GB-mediated.

The PHO1 gene is involved in loading $\mathrm{Pi}$ into the xylem of roots (Hamburger et al., 2002). As shown in Figure 8C, the transcription level of the PHO1 gene was evaluated 

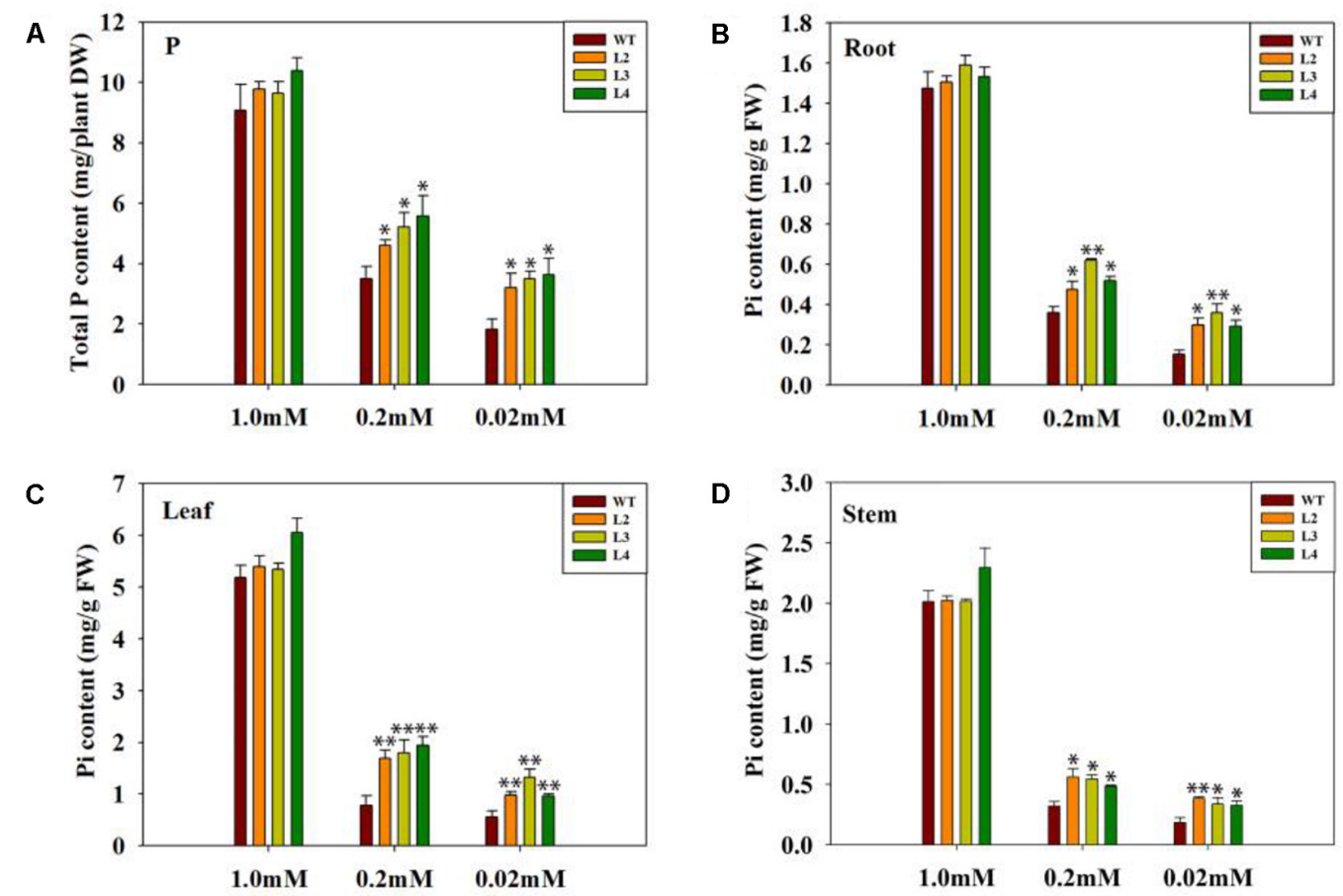

FIGURE 5 | Comparison of total P and Pi content between WT and transgenic plants. Plants were grown under variable Pi conditions for 15 days. (A) Total phosphorus content of WT and transgenic lines under different Pi concentrations. Seedlings (after germination) were treated with $1.0 \mathrm{mM}$ phosphorus (CK), $0.2 \mathrm{mM}$ phosphorus, and $0.02 \mathrm{mM}$ phosphorus (LP) for 15 days under sand-culture system. Seedlings were subsequently harvested for measuring phosphorus content. Values are means \pm SD. $n=4$ for each genotype. (B-D) The Pi content of the leaves, stem and root under normal Pi and low Pi conditions. Pi content was measured in harvested 15-day-old tomato plants. Values represent the means \pm SD of three replicates. Asterisks indicate significant differences compared with WT plants (Student's $t$-test). DW, dry weight; FW, fresh weight; ${ }^{*} P<0.05 ;{ }^{* *} P<0.01$.

TABLE 1 | The purity of plasma membrane isolated from tomato roots was analyzed by the activity of various inhibitor-sensitive ATPases in the membrane fraction.

\begin{tabular}{lcccc}
\hline & $\mathbf{N a}_{\mathbf{3}} \mathbf{V O}_{\mathbf{4}}$ & $\mathbf{K N O}_{3}$ & $\mathbf{N a N}_{\mathbf{3}}$ & $\mathbf{N a}_{\mathbf{2}} \mathbf{M o O}_{\mathbf{4}}$ \\
\hline $1.0 \mathrm{mM}$ & $0.881 \pm 0.02$ & $0.091 \pm 0.01$ & $0.057 \pm 0.05$ & $0.022 \pm 0.02$ \\
$0.2 \mathrm{mM}$ & $0.874 \pm 0.04$ & $0.079 \pm 0.02$ & $0.038 \pm 0.08$ & $0.029 \pm 0.05$ \\
$0.02 \mathrm{mM}$ & $0.91 \pm 0.02$ & $0.066 \pm 0.02$ & $0.05 \pm 0.03$ & $0.032 \pm 0.07$
\end{tabular}

The membrane was isolated from tomato roots subjected to normal and low-phosphate stress conditions. The values are the means and SD of 10 replicates from two independent experiments.

in the roots of the $\operatorname{codA}$-transgenic lines and WT plants. However, the transcription of $\mathrm{PHO1}$ was significantly enhanced in the $\operatorname{cod} A$-transgenic lines (Figure 8C), with the highest induction at $0.02 \mathrm{mM}$ and the lowest under normal conditions. The UBC24 gene was identified as $\mathrm{PHO} 2$, which negatively regulates $\mathrm{Pi}$ remobilization and uptake (Aung et al., 2006; Bari et al., 2006; Chiou et al., 2006; Zhou et al., 2017). Our results showed that the expression of $\mathrm{PHO} / \mathrm{UBC} 24$ was clearly repressed under low-phosphate conditions (Figure 8D), and the repression level of $\mathrm{PHO} / \mathrm{UBC} 24$ expression in the $\operatorname{cod} A$-transgenic lines was more marked than that in WT plants. These data indicate that GB in vivo may modulate the expression of some genes related to $\mathrm{Pi}$ uptake and translocation.

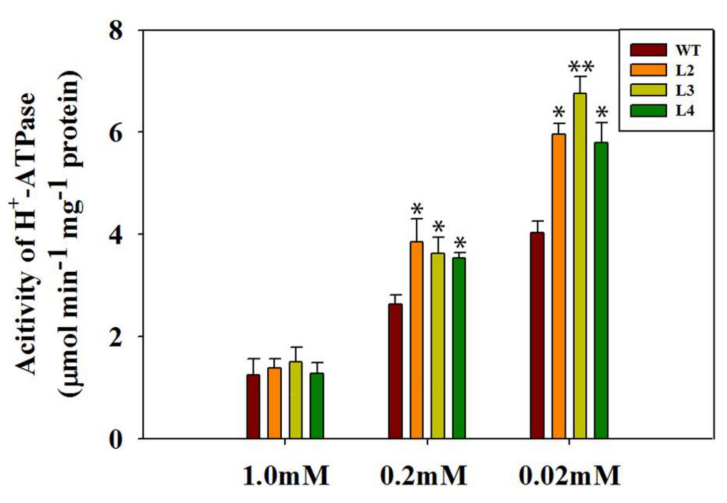

FIGURE 6 | Comparison of plasma membrane $\mathrm{H}^{+}$-ATPase activity derived from tomato roots. Seedlings (after germination) were treated with $1.0 \mathrm{mM}$ phosphorus (CK), $0.2 \mathrm{mM}$ phosphorus, and $0.02 \mathrm{mM}$ phosphorus (LP) for 15 days under a sand-culture system. Values are means \pm SD of three replications per experiment, $n=6$ for each genotype. Asterisks indicate significant differences compared with WT plants (Student's $t$-test). ${ }^{*} P<0.05$; $* * P<0.01$.

\section{DISCUSSION}

Plants require a large amount of $\mathrm{Pi}$ for their growth and development, but Pi levels are limited and constantly changing. 
A

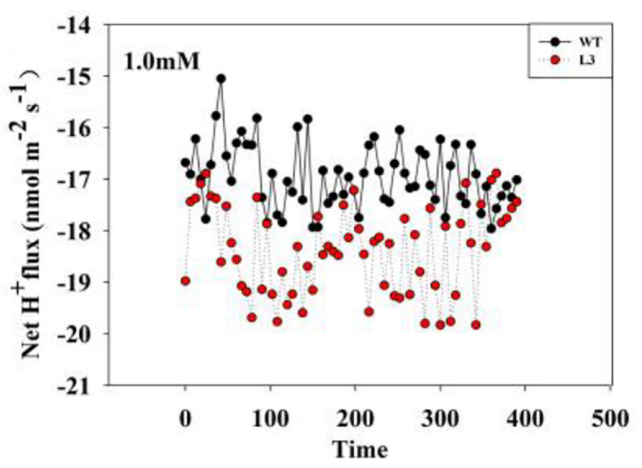

C

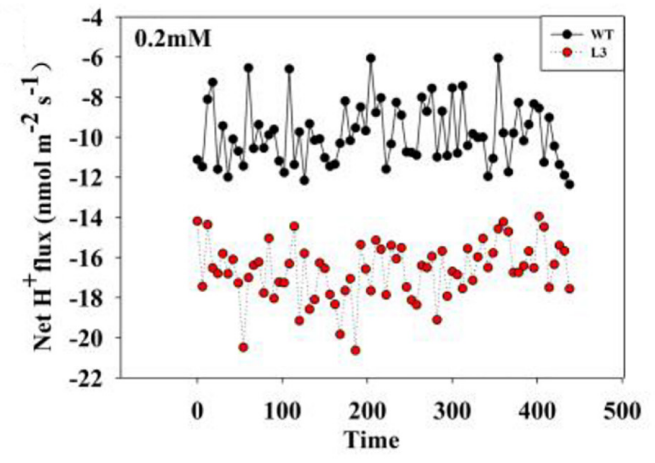

E

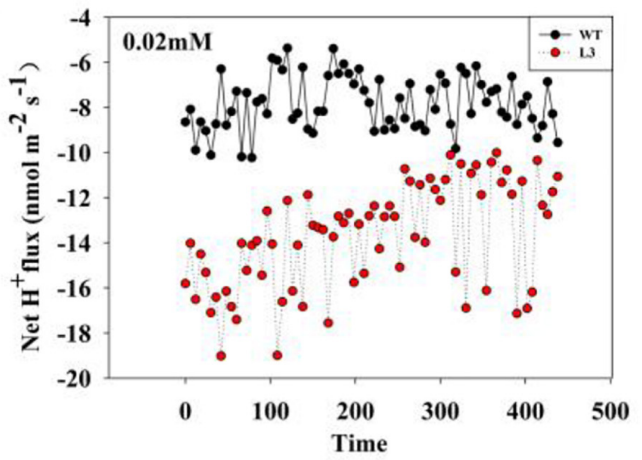

B

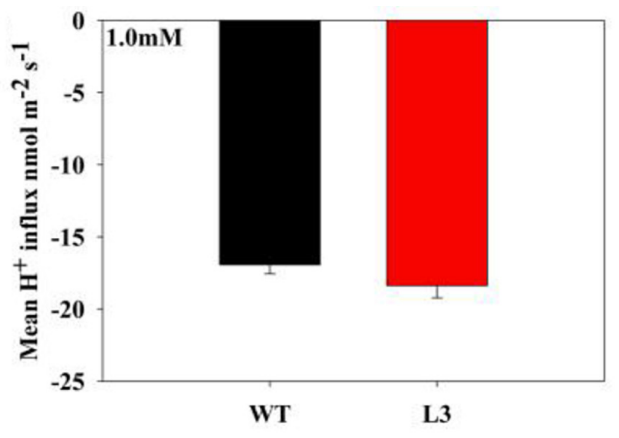

D

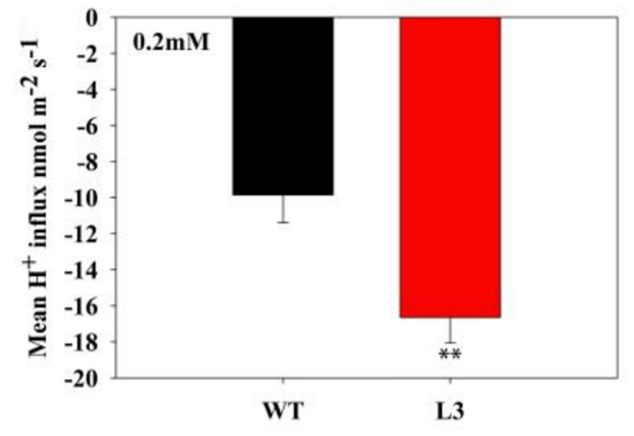

F

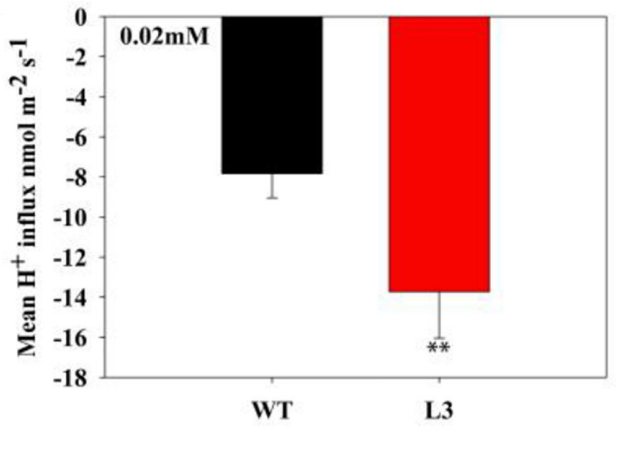

FIGURE $7 \mid \mathrm{H}^{+}$flux in tomato roots under variable Pi conditions. (A,C,E) Transient net flux of $\mathrm{H}^{+}$in the root elongation zone of WT plants and three codA-transgenic tomato lines under different Pi concentrations. A continuous flux recording over 10 min was conducted in a corresponding measuring solution (pH 6.0). (B,D,F) The mean rate of $\mathrm{H}^{+}$flux within the measuring periods is shown. Values are means $\pm \mathrm{SD}$. $n=6$ for each genotype. Asterisks indicate significant differences compared with WT plants (Student's t-test). ${ }^{*} P<0.05 ;{ }^{* *} P<0.01$.

To adapt to this nutrient stress, plants have evolved a strong $\mathrm{Pi}$ uptake and translocation capability (Liu et al., 2015). However, $\mathrm{GB}$, as an important compatible solute, plays a vital role in various forms of abiotic stresses responses (Khan et al., 2009; Giri, 2011). Phosphorus stress is one type of abiotic stress. However, the relationships between GB and mineral nutrition remain unclear, especially for elemental phosphorus. Few studies indicated that the interaction between GB and mineral nutrients can be targeted to develop a tolerant phenotype (Masood et al., 2016). In this study, we confirmed the differential Pi uptake and translocation capacity between WT and transgenic plants and proposed a novel role that GB could alleviate low-phosphorus stress.

Phosphorus deficiency is detrimental to plant growth, development and metabolism. Several reports have shown that phosphorus deficiency leads to growth retardation and lowers the Pi level in plants (Ciereszko and Barbachowska, 2000; Lei et al., 2011; Xu et al., 2012; Su et al., 2015). In this study, although the codA-transgenic plants and WT plants both displayed a Pi-deficiency phenotype (Figure 2), including the level of internal phosphorus was reduced under low-phosphate stress (Figure 5), but the $\operatorname{cod} A$-transgenic plants were rendered more resistant to low-phosphate stress. We observed that the difference is not obvious in phosphorus content between WT and the codA-transgenic plants under normal condition and the $\operatorname{codA}$-transgenic plants still maintained higher phosphorus content in the tissue compared with WT plants under low-phosphorus stress (Figure 5). This difference was probably due to that GB can affect the expression of some 


\section{A}

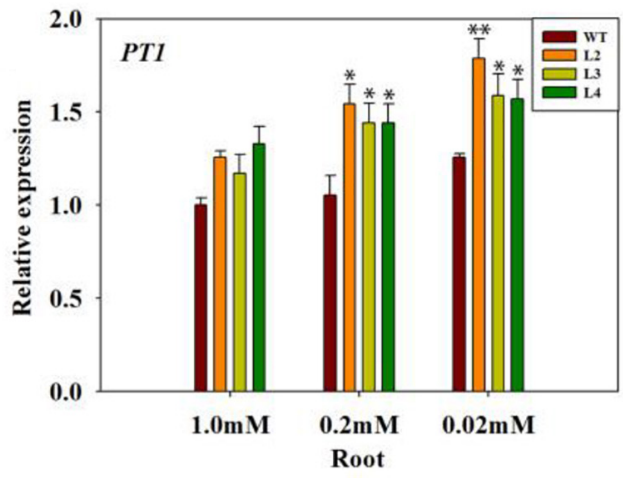

C

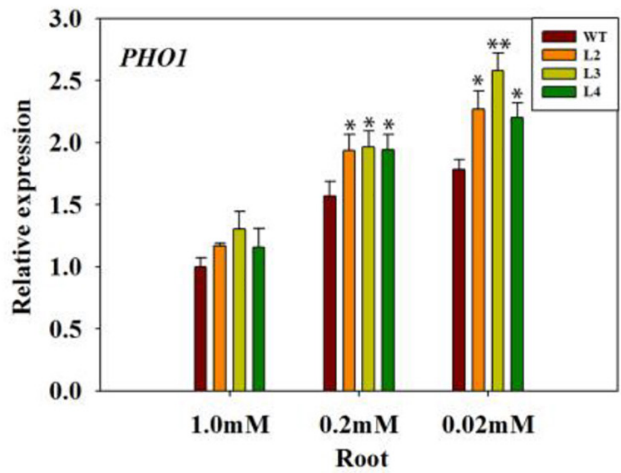

B

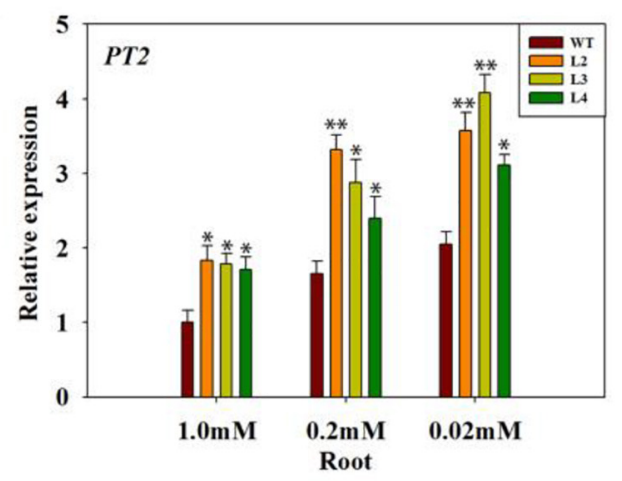

D

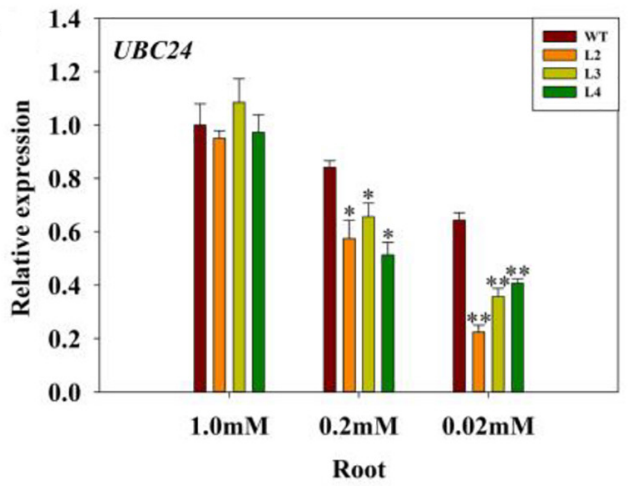

FIGURE 8 | Quantitative analysis of gene expression of PT1 (A), PT2 (B), PHO1 (C), and UBC24 (D) in the root of the WT tomato plant and three codA-transgenic tomato lines under variable Pi conditions. Seedlings (after germination) were treated with $1.0 \mathrm{mM}$ phosphorus (CK), $0.2 \mathrm{mM}$ phosphorus, and $0.02 \mathrm{mM}$ phosphorus (LP) for 15 days under a sand-culture system. Seedlings were subsequently harvested for experimental analysis. Values represent the means \pm SD of three biological replicates. Asterisks indicate significant differences compared with WT plants (Student's $t$-test). ${ }^{*} P<0.05 ;{ }^{* *} P<0.01$.

genes involved in $\mathrm{Pi}$ uptake and translocation and further promote $\mathrm{Pi}$ acquisition and translocation in low phosphorus stress condition (Figure 8). This further proved the notion that GB plays vital role in responding to low phosphate stress.

The $\operatorname{cod} A$-transgenic plants also display other characteristic responses to low phosphate levels, including reduced anthocyanin (Figure 2D) and starch (Figure 2E) accumulation. We speculated that these altered low-phosphate responses are caused by the GB accumulation in the transgenic plants (Figure 1). Numerous reports have demonstrated that GB plays a versatile and crucial role in imparting stress tolerance in plants (Takabe et al., 2006; Ahmad et al., 2013; Masood et al., 2016). Among these studies, none of them indicated that GB has any negative effects on plant growth and development under normal or stressful conditions (Ahmad et al., 2013). Therefore, we can infer that the transgenic plants suffered less under from smaller low-phosphate stress than WT plants.

Because the WT plants were smaller in stature, we suspected that this size difference could affect comparability of $\mathrm{Pi}$ measurements in the WT and transgenic plants. Thus, we next set out to determine the Pi uptake. Proton release into the rhizosphere is also a common adaptation to low phosphorus for enhancing phosphorus uptake (Raven and Smith, 1976;
Lambers et al., 2006; Richardson, 2009). Generally, the increase in $\mathrm{H}^{+}$secretion results from the activity of a plasma membrane $\mathrm{H}^{+}$-ATPase (Yan et al., 2002; Vance et al., 2003). The plasma membrane $\mathrm{H}^{+}$-ATPase plays an especially important role in the plant response to low-phosphate stress. Compared with WT plants, the transgenic plants exhibited higher activity of plasma membrane $\mathrm{H}^{+}$-ATPase low-phosphate conditions (Figure 6), suggesting that GB maybe involved in the low-phosphate response by activating root plasma membrane $\mathrm{H}^{+}$-ATPase to release protons. Several studies demonstrated that GB could positively affects complex proteins and antioxidative defense systems (Chen and Murata, 2011; Giri, 2011; Masood et al., 2016). In addition, our previous study (Wei et al., 2017) indicated that GB can regulate the $\mathrm{H}^{+}$-ATPase by enhance the expression of genes. We infer that GB accumulation due to the expression of choline oxidase in transgenic plants enhances the activity of $\mathrm{H}^{+}$-ATPase might associated with the protection to $\mathrm{H}^{+}$-ATPase and the enhancement of gene expression. However, the mechanism of how GB enhances enzyme activity remains to be further studied. The activation of the plasma membrane $\mathrm{H}^{+}$-ATPase may enhance the transport of phosphorus via establishing an electrochemical proton gradient that drives ion transport across the plant cell membrane (Haruta and Sussman, 2012; Yuan et al., 2017). Therefore, it is feasible to hypothesize that more $\mathrm{H}^{+}$may be involved in Pi transport across the plasma 
membrane in the transgenic roots under low-phosphate stress, which facilitates Pi uptake. This inference is further supported by the enhanced $\mathrm{H}^{+}$influx in the transgenic lines (Figure 7). Considering the stronger values of $\mathrm{H}^{+}$influx in transgenic roots, we presume that more $\mathrm{H}^{+}$do carry more $\mathrm{Pi}$ into the plant cell under low-phosphate conditions. This hypothesis is also confirmed by the phosphorus and $\mathrm{Pi}$ content measured in this paper (Figure 5). Wei et al. (2017) found that GB also regulated $\mathrm{H}^{+}$-ATPase activity in the $\operatorname{cod} A$-transgenic tomato lines under salt stress, to enhance $\mathrm{Na}^{+}$exclusion and $\mathrm{K}^{+}$uptake. In addition, growing evidence suggests that GB has a certain impact on ion absorption, including $\mathrm{Na}, \mathrm{K}, \mathrm{Ca}$ and others (Gobinathan et al., 2009; Alikhani et al., 2011; Wei et al., 2017). Therefore, we believe that $\mathrm{GB}$ can mediate $\mathrm{Pi}$ uptake by regulating proton circulation.

To further confirm that GB mediates Pi influx into plant cells, we measured the expression of SIPT1 and SIPT2 in the tomato roots, since the induction of SIPT1 and SIPT2 increased phosphate uptake (Liu et al., 1998). Interestingly, the results above showed that the transgenic tomato roots enhanced $\mathrm{Pi}$ uptake and root Pi content. In fact, the expression of SIPT1 and SIPT2 was also significantly induced in the transgenic lines in response to low-phosphate conditions (Figures 8A,B), showing that GB may modulate $\mathrm{Pi}$ uptake by directly up-regulating SlPT1 and SIPT2 expression. Pi homeostasis in plants depends not only on $\mathrm{Pi}$ influx into cells but also on Pi efflux. Proper distribution of $\mathrm{Pi}$ among the various plant tissues requires the loading and unloading of $\mathrm{Pi}$ in the xylem and phloem. The genes $\mathrm{PHO} 1$ and $\mathrm{PHO} 2$ have been identified as important to the control of Pi homeostasis (Hamburger et al., 2002; Aung et al., 2006; Bari et al., 2006). In addition, the PHO1 gene has been demonstrated to transfer Pi into the xylem of roots (Poirier et al., 1991; Hamburger et al., 2002; Ribot et al., 2008). Then, we hypothesized that the improved $\mathrm{Pi}$ content in the stem and leaf of the $\operatorname{codA}$-transgenic lines was partially caused by the differential expression of 'PHO regulon' genes. We noticed that the expression levels of $\mathrm{PHO1}$ in WT plants were clearly lower than that of transgenic lines even when they are grown under $\mathrm{Pi}$-sufficient conditions (Figure 8C). In addition, reduced PHO1 expression caused by $\mathrm{PHO} 1$ mutations impedes Pi uptake (Liu et al., 2012), which also accounts for lower root Pi content of WT plants. The results provided evidence that GB may participate in the transport of $\mathrm{Pi}$. In addition, down-regulated PHO2/UBC24 alleviates the repression of Pi transporter genes and alters root growth and architecture to maximize Pi uptake (Aung et al., 2006; Bari et al., 2006; Sunkar et al., 2007; Wang Z. et al., 2009). The repression level of $P H O 2 / U B C 24$ was slightly stronger in the $\operatorname{cod} A$-transgenic lines (Figure 8D), which was consistent with their phenotype of higher expression of $\mathrm{Pi}$ transporter genes, stronger Pi uptake and translocation and better root development compared with WT seedlings. Previously, several studies have provided convincing evidence that the GB-accumulating transgenic plants have enhanced expression of stress-responsive genes (Kathuria et al., 2009; Chen and Murata, 2011; Giri, 2011), which might be a plausible explanation for GB-mediated genes related to $\mathrm{Pi}$ uptake and redistribution. These results further supported the speculation that GB plays an important role in Pi uptake and translocation under low Pi stress condition.

It is generally known that $\mathrm{Pi}$ deficiency has direct consequences for photosynthesis. Interestingly, GB has previously been reported to protect photosynthetic machinery in response to various type of environmental stresses (Bartels and Sunkar, 2005; Chaum and Kirdmanee, 2010; Chaum et al., 2013; Masood et al., 2016). In this work, we noticed that the transgenic plants exhibit better tolerance phenotypes than do WT plants, especially in the case of severe low-phosphate conditions (Figures 2A,B), and thus we naturally speculate that it may be closely related to the strong photosynthetic and metabolic processes in transgenic plants. As expected, physiological parameters showed that photosynthetic activity and fresh weight were significantly higher in transgenic plants compared with WT plants under low-phosphate conditions (Figures 2C, 4). Sucrose derived from photosynthesis serves not only as the major form of carbohydrate for long-distance translocation but also as a systemic signal of $\mathrm{Pi}$ signaling (Hammond and White, 2008; Zhang et al., 2014). Sucrose transport requires active loading, unloading and utilization of sucrose in the sink tissues. We found that low-phosphate stress enhanced the activities of sucrose synthesis enzymes, especially in the transgenic lines (Figures 3B,C). These data are consistent with sucrose content in both WT and transgenic plants (Figure 3A). In our work, a significantly higher SUC2 expression in the leaves of phosphorus-starved transgenic plants was also observed (Figure 3D). SUC2 encodes a sucrose-proton symporter that is responsible for sucrose loading into the phloem (Gottwald et al., 2000; Lloyd and Zakhleniuk, 2004). Wissuwa et al. (2005) speculated that the increased translocation of sucrose to the root may be driven by an increased root demand and that sucrose is likely to be utilized immediately by roots. Consequently, the transgenic lines with higher shoot sucrose concentration and better transport enable the plants to meet their need for root growth and to maximize $\mathrm{Pi}$ uptake, while lower sucrose biosynthesis and/or translocation attenuates plant response to low-phosphate stress in the WT plants. This is also consistent with the root phenotype results

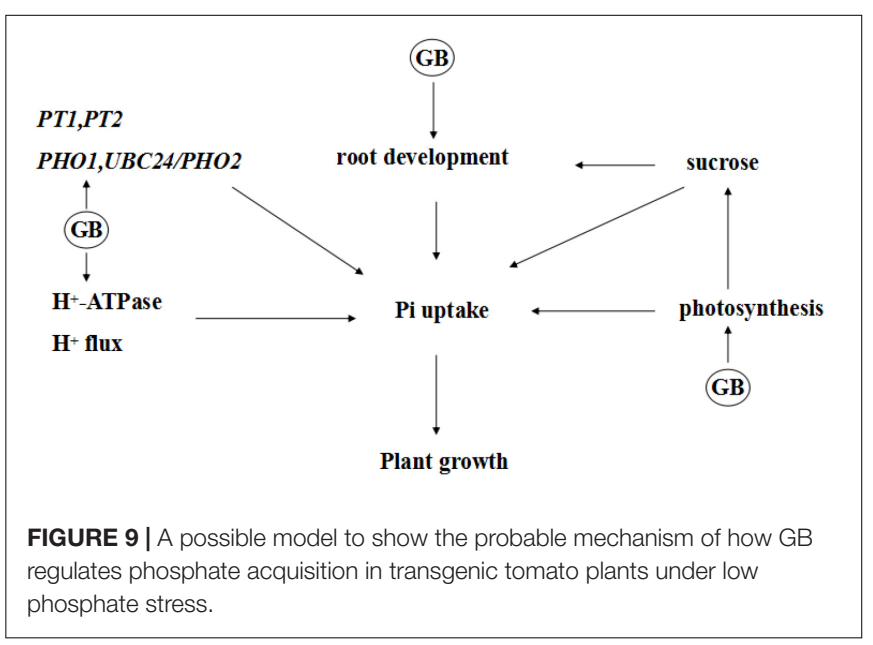


obtained under low-phosphate conditions (Figure 2B). Between root development and photosynthesis, a mutually beneficial relationship in the transgenic lines is established. Taken together, our results suggest that GB is involved in the response of plants to low-phosphate conditions via regulating leaf carbon allocation and sucrose transport to promote root growth.

\section{CONCLUSION}

In summary, we investigated the potential mechanisms that GB mediates low Pi tolerance (Figure 9). We demonstrated that accumulated GB in transgenic tomato plants can alter the uptake of $\mathrm{Pi}$; carbohydrate signaling; the expression of low-phosphate-response genes that are involved in Pi signaling, transport, mobilization; and the Pi balance between roots and shoots, which will ultimately maintain Pi homeostasis and help plant better adapt to low phosphate stress. A challenging task ahead is to identify the direct targets of GB and understand how GB perceives and transmits low $\mathrm{Pi}$ signaling to trigger plant $\mathrm{Pi}$ responses at the molecular level. Our result may benefit effort to enhance phosphate utilization efficiency of plant as well as to improve crop yield in low phosphate regions.

\section{REFERENCES}

Ahmad, R., Lim, C. J., and Kwon, S. Y. (2013). Glycine betaine: a versatile compound with great potential for gene pyramiding to improve crop plant performance against environmental stresses. Plant Biotechnol. Rep. 7, 49-57. doi: $10.1007 / \mathrm{s} 11816-012-0266-8$

Ai, P., Sun, S., Zhao, J., Fan, X., Xin, W., Guo, Q., et al. (2009). Two rice phosphate transporters, Ospht1;2 and Ospht1;6, have different functions and kinetic properties in uptake and translocation. Plant J. 57, 798-809. doi: 10. 1111/j.1365-313X.2008.03726.x

Alikhani, F., Saboora, A., and Razavi, K. (2011). Changes in osmolytes contents, lipid peroxidation and photosynthetic pigment of Aeluropus lagopoides under potassium deficiency and salinity. J. Stress Physiol. Biochem. 7, 5-19.

Ames, B. N. (1966). Assay of inorganic phosphate, total phosphate and phosphatases. Method Enzymol. 8, 115-118. doi: 10.1016/0076-6879(66) 08014-5

Aung, K., Lin, S. I., Wu, C. C., Huang, Y. T., Su, C. L., and Chiou, T. J. (2006). Pho2, a phosphate overaccumulator, is caused by a nonsense mutation in a microRNA399 target gene. Plant Physiol. 141, 1000-1011. doi: 10.1104/pp.106. 078063

Bari, R., Pant, B. D., Stitt, M., and Scheible, W. R. (2006). PHO2, microRNA399, and PHR1 define a phosphate-signaling pathway in plants. Plant Physiol. 141, 988-999. doi: 10.1104/pp.106.079707

Bartels, D., and Sunkar, R. (2005). Drought and salt tolerance in plants. Crit. Rev. Plant Sci. 24, 23-58. doi: 10.1080/07352680590910410

Bradford, M. M. (1976). A rapid and sensitive method for the quantitation of microgram quantities of protein utilizing the principle of protein-dye binding. Anal. Biochem. 72, 248-254. doi: 10.1016/0003-2697(76)90527-3

Bucher, M., and Fabiańska, I. (2016). Long-sought vacuolar phosphate transporters identified. Trends Plant Sci. 21, 463-466. doi: 10.1016/j.tplants.2016.04.011

Chaum, S., and Kirdmanee, C. (2010). Effect of glycinebetaine on proline, water use, and photosynthetic efficiencies, and growth of rice seedlings under salt stress. Turk J. Agric. For. 34, 517-527. doi: 10.3906/tar-0906-34

Chaum, S., Samphumphuang, T., and Kirdmanee, C. (2013). Glycinebetaine alleviates water deficit stress in indica rice using proline accumulation, photosynthetic efficiencies, growth performances and yield attributes. Aust. J. Crop Sci. 7, 213-218.

Chen, A., Chen, X., Wang, H., Liao, D., Gu, M., Qu, H., et al. (2014). Genomewide investigation and expression analysis suggest diverse roles and genetic

\section{AUTHOR CONTRIBUTIONS}

$\mathrm{XY}$ and TC designed the experiments. DL performed the experiments with the help of TZ and MW. DL and XY wrote the manuscript. $\mathrm{MB}$ and $\mathrm{YL}$ gave positive suggestion about this article. All authors read and approved the manuscript.

\section{FUNDING}

This work was supported by the National Natural Science Foundation of China (Grant Nos. 30970299, 31470341, and 31870216), the State Key Basic Research and Development Plan of China (Grant No. 2015CB150105), and the Research in Chen's laboratory was supported by the Oregon Agricultural Experiment Station.

\section{SUPPLEMENTARY MATERIAL}

The Supplementary Material for this article can be found online at: https://www.frontiersin.org/articles/10.3389/fpls.2018.01995/ full\#supplementary-material

redundancy of Pht1 family genes in response to Pi deficiency in tomato. BMC Plant Biol. 14:61. doi: 10.1186/1471-2229-14-61

Chen, T. H. H., and Murata, N. (2002). Enhancement of tolerance to abiotic stress by metabolic engineering of betaines and other compatible solutes. Curr. Opin. Plant Biol. 5, 250-257. doi: 10.1016/S1369-5266(02)00255-8

Chen, T. H. H., and Murata, N. (2008). Glycinebetaine: an effective protectant against abiotic stress in plants. Trends Plant Sci. 13, 499-505. doi: 10.1016/j. tplants.2008.06.007

Chen, T. H. H., and Murata, N. (2011). Glycinebetaine protects plants against abiotic stress: mechanisms and biotechnological applications. Plant Cell Environ. 34, 1-20. doi: 10.1111/j.1365-3040.2010.02232.x

Chiou, T. J., Aung, K., Lin, S. I., Wu, C. C., Chiang, S. F., and Su, C. L. (2006). Regulation of phosphate homeostasis by MicroRNA in Arabidopsis. Plant Cell 18, 412-421. doi: 10.1105/tpc.105.038943

Chiou, T. J., and Lin, S. I. (2011). Signaling network in sensing phosphate availability in plants. Annu. Rev. Plant Biol. 62, 185-206. doi: 10.1146/annurevarplant-042110-103849

Ciereszko, I., and Barbachowska, A. (2000). Sucrose metabolism in leaves and roots of bean (Phaseolus vulgaris L.) during phosphate deficiency. J. Plant Physiol. 156, 640-644. doi: 10.1016/S0176-1617(00)80225-4

Giri, J. (2011). Glycinebetaine and abiotic stress tolerance in plants. Plant Signal. Behav. 6, 1746-1751. doi: 10.4161/psb.6.11.17801

Gobinathan, P., Murali, P. V., and Panneerselvam, R. (2009). Interactive effects of calcium chloride on salinity-induced proline metabolism in Pennisetum typoidies. Bot. Res. Intl. 3, 168-173.

Gong, Y. M., Guo, Z. H., He, L. Y., and Li, J. S. (2011). Identification of maize genotypes with high tolerance or sensitivity to phosphorus deficiency. J. Plant Nutr. 34, 1290-1302. doi: 10.1080/01904167.2011.580816

Gottwald, J. R., Krysan, P. J., Young, J. C., Evert, R. F., and Sussman, M. R. (2000). Genetic evidence for the in planta role of phloem-specific plasma membrane sucrose transporters. Proc. Natl. Acad. Sci. U.S.A. 97, 13979-13984. doi: 10. 1073/pnas.250473797

Hamburger, D., Rezzonico, E., MacDonald-Comber, P. J., Somerville, C., and Poirier, Y. (2002). Identification and characterization of the Arabidopsis PHO1 gene involved in phosphate loading to the xylem. Plant Cell 14, 889-902. doi: 10.1105/tpc.000745

Hammond, J. P., and White, P. J. (2008). Sucrose transport in the phloem: integrating root responses to phosphorus starvation. J. Exp. Bot. 59, 93-109. doi: $10.1093 / \mathrm{jxb} / \mathrm{erm} 221$ 
Haruta, M., and Sussman, M. R. (2012). The effect of a genetically reduced plasma membrane protonmotive force on vegetative growth of Arabidopsis. Plant Physiol. 158, 1158-1171. doi: 10.1104/pp.111.189167

Kathuria, H., Giri, J., Nataraja, K. N., Murata, N., Udayakumar, M., and Tyagi, A. K. (2009). Glycinebetaine-induced water-stress tolerance in codAexpressing transgenic indica rice is associated with up-regulation of several stress responsive genes. Plant Biotechnol. J. 7, 512-526. doi: 10.1111/j.14677652.2009.00420.x

Khan, M. S., Yu, X., Kikuchi, A., Asahina, M., and Watanabe, K. N. (2009). Genetic engineering of glycine betaine biosynthesis to enhance abiotic stress tolerance in plants. Plant Biotechnol. 26, 125-134. doi: 10.5511/plantbiotechnology.26.125

Kumar, V., Shriram, V., Hoque, T. S., Hasan, M. M., Burritt, D. J., and Hossain, M. A. (2017). "Glycinebetaine-mediated abiotic oxidative-stress tolerance in plants: physiological and biochemical mechanisms," in Stress Signaling in Plants: Genomics and Proteomics Perspective, Vol. 2, eds M. Sarwat, A. Ahmad, M. Abdin, and M. Ibrahim (Cham: Springer International Publishing), 111-133. doi: 10.1007/978-3-319-42183-4-5

Kurepin, L. V., Ivanov, A. G., Zaman, M., Pharis, R. P., Allakhverdiev, S. I., Hurry, V., et al. (2015). Stress-related hormones and glycinebetaine interplay in protection of photosynthesis under abiotic stress conditions. Photosynth. Res. 126, 221-235. doi: 10.1007/s11120-015-0125-x

Lambers, H., Shane, M. W., Cramer, M. D., Pearse, S. J., and Veneklaas, F. J. (2006). Root structure and functioning for efficient acquisition of phosphorus: matching morphological and physiological trait. Ann. Bot. 98, 693-713. doi: $10.1093 / \mathrm{aob} / \mathrm{mcl} 114$

Lei, M., Liu, Y., Zhang, B., Zhao, Y., Wang, X., Zhou, Y., et al. (2011). Genetic and genomic evidence that sucrose is a global regulator of plant responses to phosphate starvation in Arabidopsis. Plant Physiol. 156, 1116-1130. doi: 10.1104/pp.110.171736

Li, M. F., Guo, S. J., Xu, Y., Meng, Q. W., Li, G., and Yang, X. H. (2014). Glycine betaine-mediated potentiation of HSP gene expression involves calcium signaling pathways in tobacco exposed to $\mathrm{NaCl}$ stress. Physiol. Plant. 150, 63-75. doi: $10.1111 /$ ppl.12067

Li, S. F., Li, F., Wang, J. W., Zhang, W., Meng, Q. W., Chen, T. H. H., et al. (2011). Glycinebetaine enhances the tolerance of tomato plants to high temperature during germination of seeds and growth of seedlings. Plant Cell Environ. 34, 1931-1943. doi: 10.1111/j.1365-3040.2011.02389.x

Lin, W. Y., Lin, S. I., and Chiou, T. J. (2009). Molecular regulators of phosphate homeostasis in plants. J. Exp. Bot. 60, 1427-1438. doi: 10.1093/jxb/ern303

Liu, C., Muchhal, U. S., Uthappa, M., Kononowicz, A. K., and Raghothama, K. G. (1998). Tomato phosphate transporter genes are differentially regulated in plant tissues by phosphorus. Plant Physiol. 116, 91-99. doi: 10.1104/pp.116.1.91

Liu, J. L., Yang, L., Luan, M. D., Wang, Y., Zhang, C., Zhang, B., et al. (2015). A vacuolar phosphate transporter essential for phosphate homeostasis in Arabidopsis. Proc. Natl. Acad. Sci. U.S.A. 112, 6571-6578. doi: 10.1073/pnas. 1514598112

Liu, T. Y., Huang, T. K., Tseng, C. Y., Lai, Y. S., Lin, S. I., Lin, W. Y., et al. (2012). $\mathrm{PHO} 2$-dependent degradation of PHO1 modulates phosphate homeostasis in Arabidopsis. Plant Cell 24, 2168-2183. doi: 10.1105/tpc.112.096636

Lloyd, J. C., and Zakhleniuk, O. V. (2004). Responses of primary and secondary metabolism to sugar accumulation revealed by microarray expression analysis of the Arabidopsis mutant, pho3. J. Exp. Bot. 55, 1221-1230. doi: 10.1093/jxb/ erh 143

Löffler, A., Abel, S., Jost, W., Beintema, J. J., and Glund, K. (1992). Phosphate-regulated induetion of intraeellular ribonucleases in cultured tomato (Lycopersicon seculentum) cell. Plant Physiol. 98, 1472-1478.

Löffler, A., Glund, K., and Irie, M. (1993). Amino acid sequence of an intracellular, phosphate-starvation-induced ribonuclease from cultured tomato (Lycopersicon esculentum) cells. Eur. J. Biochem. 214, 627-633.

López-Arredondo, D. L., Leyva-González, M. A., González-Morales, S. I., LópezBucio, J., and Herrera-Estrella, L. (2014). Phosphate nutrition: improving low-phosphate tolerance in crops. Annu. Rev. Plant Biol. 65, 95-123. doi: 10. 1146/annurev-arplant-050213-035949

Masood, A., Per, T. S., Asgher, M., Fatma, M., Khan, M. I. R., Rasheed, F., et al. (2016). "Glycine betaine: role in shifting plants toward adaptation under extreme environments," in Osmolytes and Plants Acclimation to Changing Environment: Emerging Omics Technologies, eds N. Iqbal, R. A. Nazar, and N. Khan (New Delhi: Springer), 69-82. doi: 10.1007/978-81-322-2616-1_5
Mehra, P., Pandey, B. K., and Giri, J. (2016). Comparative morphophysiological analyses and molecular profiling reveal pi-efficient strategies of a traditional rice genotype. Front. Plant Sci. 6:1184. doi: 10.3389/fpls.2015.01184

Mehra, P., Pandey, B. K., and Giri, J. (2017). Improvement of phosphate acquisition and utilization by a secretory purple acid phosphatase (OsPAP21b) in Rice. Plant Biotechnol. J. 15, 1054-1067. doi: 10.1111/pbi.12699

Nussaume, L., Kanno, S., Javot, H., Marin, E., Pochon, N., Ayadi, A., et al. (2011). Phosphate import in plants: focus on the PHT1 transporters. Front. Plant Sci. 2:83. doi: $10.3389 /$ fpls.2011.00083

Otani, T., Ae, N., and Tanaka, H. (1996). P uptake mechanisms of crop grown in soils with low P status. II. Significance of organic acids in root exudates of pigeonpea. Soil Sci. Plant Nutr. 42, 533-560. doi: 10.1080/00380768.1996. 10416324

Pandey, B. K., Mehra, P., Verma, L., Bhadouria, J., and Giri, J. (2017). OsHAD1, a haloacid dehalogenase-like apase, enhances phosphate accumulation. Plant Physiol. 174, 2316-2332. doi: 10.1104/pp.17.00571

Park, E. J., Jeknić, Z., Chen, T. H., and Murata, N. (2007). The codA transgene for glycinebetaine synthesis increases the size of flowers and fruits in tomato. Plant Biotechnol. J. 5, 422-430. doi: 10.1111/j.1467-7652.2007.00251.x

Park, E. J., Jeknic, Z., Sakamoto, A., DeNoma, J., Yuwansiri, R., Murata, N., et al. (2004). Genetic engineering of glycinebetaine synthesis in tomato protects seeds, plants, and flowers from chilling damage. Plant J. 40, 474-487. doi: 10.1111/j.1365-313X.2004.02237.x

Plaxton, W. C., and Carswell, M. C. (1999). "Metabolic aspects of phosphate starvation in plants," in Plant Responses to Environmental Stresses: from Phytohormones to Genome Reorganization, ed. H. R. Lerner (New York, NY: Marcel Dekker), 349-372.

Plaxton, W. C., and Tran, H. T. (2011). Metabolic adaptations of phosphate-starved plants. Plant Physiol. 156, 1006-1015. doi: 10.1104/pp.111.175281

Poirier, Y., Thoma, S., Somerville, C., and Schiefelbein, J. (1991). A mutant of Arabidopsis deficient in xylem loading of phosphate. Plant Physiol. 97, 1087-1093. doi: 10.1104/pp.97.3.1087

Rabino, I., and Mancinelli, A. L. (1986). Light, temperature, and anthocyanin production. Plant Physiol. 81, 922-924. doi: 10.1104/pp.81.3.922

Raghothama, K. G. (1999). Phosphate acquisition. Annu. Rev. Plant Biol. 50, 665-693. doi: 10.1146/annurev.arplant.50.1.665

Raghothama, K. G. (2000). Phosphate transport and signaling. Curr. Opin. Plant Biol. 3, 182-187. doi: 10.1016/S1369-5266(00)80063-1

Raven, J. A., and Smith, F. A. (1976). Nitrogen assimilation and transport in vascular land plants in relation to intracellular $\mathrm{pH}$ regulation. New Phytol. 76, 415-431. doi: : 10.1111/j.1469-8137.1976.tb01477.x

Rhodes, D., Rich, P. J., Brunk, D. G., Rhodes, J. C., Pauly, M. H., and Hansen, L. A. (1989). Development of two isogenic sweet corn hybrids differing for glycinebetaine content. Plant Physiol. 91, 1112-1121. doi: 10.1104/pp.91.3.1112

Ribot, C., Wang, Y., and Poirier, Y. (2008). Expression analyses of three members of the AtPHO1 family reveal differential interactions between signaling pathways involved in phosphate deficiency and the responses to auxin, cytokinin, and abscisic acid. Planta 227, 1025-1036. doi: 10.1007/s00425-007-0677-x

Richardson, A. E. (1994). Soil microorganisms and phosphorus availability. Soil Biota 50, 35-39.

Richardson, A. E. (2009). Regulating the phosphorus nutrition of plants: molecular biology meeting agronomic needs. Plant Soil 322, 17-24. doi: 10.1007/s11104009-0071-5

Shen, J. B., Yuan, L. X., Zhang, J. L., Li, H. G., Bai, Z. H., Chen, X. P., et al. (2011). Phosphorus dynamics: from soil to plant. Plant Physiol. 156, 997-1005. doi: 10.1104/pp.111.175232

Shin, H., Shin, H. S., Dewbre, G. R., and Harrison, M. J. (2004). Phosphate transport in Arabidopsis: Pht1;1 and Pht1;4 play a major role in phosphate acquisition from both low- and high-phosphate environments. Plant J. 39, 629-642. doi: 10.1111/j.1365-313X.2004.02161.x

Song, L., Yu, H., Dong, J., Che, X., Jiao, Y., and Liu, D. (2016). The molecular mechanism of ethylene-mediated root hair development induced by phosphate starvation. PLoS Genet. 12:e1006194. doi: 10.1371/journal.pgen.100 6194

Su, T., Xu, Q., Zhang, F. C., Chen, Y., Li, L. Q., Wu, W. H., et al. (2015). WRKY42 modulates phosphate homeostasis through regulating phosphate translocation and acquisition in Arabidopsis. Plant Physiol. 167, 1579-1591. doi: 10.1104/pp. 114.253799 
Sunkar, R., Chinnusamy, V., Zhu, J., and Zhu, J. K. (2007). Small RNAs as big players in plant abiotic stress responses and nutrient deprivation. Trends Plant Sci. 12, 301-309. doi: 10.1016/j.tplants.2007.05.001

Takabe, T., Rai, V., and Hibino, T. (2006). "Metabolic engineering of glycinebetaine," in Abiotic Stress Tolerance in Plants, eds A. K. Rai and T. Takabe (Dordrecht: Springer), 137-151. doi: 10.1007/1-4020-4389-9_9

Tian, J., Liao, H., Wang, X., and Yan, X. (2003). Phosphorus starvation-induced expression of leaf acid phosphates isoforms in soybean. Acta Bot. Sin. 45, 1037-1042.

Vance, C. P., Uhde-Stone, C., and Allan, D. (2003). Phosphorus acquisition and use: critical adaptations by plants for securing a nonrenewable resource. New Phytol. 157, 423-447. doi: 10.1046/j.1469-8137.2003.00695.x

Wang, X., Wang, Y., Tian, J., Lim, B. L., Yan, X., and Liao, H. (2009). Overexpressing AtPAP15 enhances phosphorus efficiency in soybean. Plant Physiol. 151, 233-240. doi: 10.1104/pp.109.138891

Wang, Z., Hu, H., Huang, H., Duan, K., Wu, Z., and Wu, P. (2009). Regulation of OsSPX1 and OsSPX3 on expression of OsSPX domain genes and Pi-starvation signaling in rice. J. Integr. Plant Biol. 51, 663-674. doi: 10.1111/j.1744-7909. 2009.00834.x

Watanabe, T., Osaki, M., Yano, H., and Rao, I. M. (2006). Internal mechanisms of plant adaptation to aluminum toxicity and phosphorus starvation in three tropical forages. J. Plant Nutr. 29, 1243-1255. doi: 10.1080/01904160600767484

Wei, D., Zhang, W., Wang, C., Meng, Q., Li, G., Chen, T. H., et al. (2017). Genetic engineering of the biosynthesis of glycinebetaine leads to alleviate salt-induced potassium efflux and enhances salt tolerance in tomato plants. Plant Sci. 257, 74-83. doi: 10.1016/j.plantsci.2017.01.012

Wissuwa, M., Gamat, G., and Ismail, A. M. (2005). Is root growth under phosphorus deficiency affected by source or sink limitations? J. Exp. Bot. 56, 1943-1950. doi: 10.1093/jxb/eri189

Xiao, K., Katagi, H., Harrison, M., and Wang, Z. Y. (2006). Improved phosphorous acquisition and biomass production in Arabidopsis by transgenic expression of a purple acid phosphate gene from M. truncatula. Plant Sci. 170, 191-202. doi: 10.1016/j.plantsci.2005.08.001

Xu, W., Shi, W., Jia, L., Liang, J., and Zhang, J. (2012). TFT6 and TFT7, two different members of tomato 14-3-3 gene family, play distinct roles in plant adaption to low phosphorus stress. Plant Cell Environ. 35, 1393-1406. doi: 10.1111/j.1365-3040.2012.02497.x

Yan, F., Zhu, Y., Mueller, C., and Schubert, S. (2002). Adaptation of H+ pumping and plasma membrane $\mathrm{H}+$-ATPase activity in proteoid roots of white lupin under phosphate deficiency. Plant Physiol. 129, 50-63. doi: 10.1104/pp.010869
Yang, X. H., Liang, Z., and Lu, C. M. (2005). Genetic engineering of the biosynthesis of glycinebetaine enhances photosynthesis against high temperature stress in transgenic tobacco plants. Plant Physiol. 138, 2299-2309. doi: 10.1104/pp.105. 063164

Yang, X. H., Liang, Z., Wen, X. G., and Lu, C. M. (2008). Genetic engineering of the biosynthesis of glycinebetaine leads to increased tolerance of photosynthesis to salt stress in transgenic tobacco plants. Plant Mol. Biol. 66, 73-86. doi: 10.1007/s11103-007-9253-9

Yang, X. H., Wen, X. G., Gong, H. M., Lu, Q. T., Yang, Z. P., Tang, Y. L., et al. (2007). Genetic engineering of the biosynthesis of glycinebetaine enhances thermotolerance of photosystem II in tobacco plant. Planta 225, 719-733. doi: 10.1007/s00425-006-0380-3

Yuan, W., Zhang, D., Song, T., Xu, F., Lin, S., Xu, W., et al. (2017). Arabidopsis plasma membrane $\mathrm{H}+$-ATPase genes AHA2 and AHA7 have distinct and overlapping roles in the modulation of root tip $\mathrm{H}+$ efflux in response to low-phosphorus stress. J. Exp. Bot. 8, 1731-1741. doi: 10.1093/jxb/erx040

Yun, S. J., and Kaeppler, S. M. (2001). Induction of maize acid phosphatase activities under phosphorus starvation. Plant Soil 237, 109-115. doi: 10.1023/A: 1013329430212

Zhang, R., Liu, G., Wu, N., Gu, M., Zeng, H., Zhu, Y., et al. (2011). Adaptation of plasma membrane $\mathrm{H}+$-ATPase and $\mathrm{H}+$ pump to $\mathrm{P}$ deficiency in rice roots. Plant Soil 349, 3-11. doi: 10.1007/s11104-011-0774-2

Zhang, Z. L., Liao, H., and Lucas, W. J. (2014). Molecular mechanisms underlying phosphate sensing, signaling, and adaptation in plants. J. Integr. Plant Biol. 56, 192-220. doi: 10.1111/jipb.12163

Zhou, B., Mural, R. V., Chen, X., Oates, M. E., Connor, R. A., Martin, G. B., et al. (2017). A subset of ubiquitin-conjugating enzymes is essential for plant immunity. Plant Physiol. 173, 1371-1390. doi: 10.1104/pp.16.01190

Conflict of Interest Statement: The authors declare that the research was conducted in the absence of any commercial or financial relationships that could be construed as a potential conflict of interest.

Copyright (c) 2019 Li, Zhang, Wang, Liu, Brestic, Chen and Yang. This is an openaccess article distributed under the terms of the Creative Commons Attribution License (CC BY). The use, distribution or reproduction in other forums is permitted, provided the original author(s) and the copyright owner(s) are credited and that the original publication in this journal is cited, in accordance with accepted academic practice. No use, distribution or reproduction is permitted which does not comply with these terms. 